\title{
External Innovation Implementation Determinants and Performance Measurement: A Case Study from the Pharmaceutical Industry
}

\author{
Matthew Coates ${ }^{1}$, Lydia Bals ${ }^{2}$ \\ ${ }^{1}$ Imperial College Business School, Imperial College, London, UK \\ ${ }^{2}$ Department of Strategic Management and Globalization, Copenhagen Business School (CBS), Copenhagen, Denmark \\ Email: lb.smg@cbs.dk
}

Received November 25, 2012; revised January 29, 2013; accepted February 6, 2013

Copyright (C) 2013 Matthew Coates, Lydia Bals. This is an open access article distributed under the Creative Commons Attribution License, which permits unrestricted use, distribution, and reproduction in any medium, provided the original work is properly cited.

\begin{abstract}
With an increasing amount of externally sourced innovations, a major success factor for innovation-dependent industries such as the pharmaceutical industry is to successfully implement innovations from outside. Existing frameworks emphasize creating a strong climate for implementation by developing the learning capabilities of the organization, but there is still much to be learned about the process of implementing innovations that have been in-sourced by companies. As a research setting that is particularly innovation-driven and not well-studied yet, this study examines the key determinants for innovation implementation based on a case study in the pharmaceutical industry. The results of 25 expert interviews and a survey with 67 respondents led to the resulting framework and a corresponding performance measurement system. The results reveal the importance of supporting systems and show differences in perception of early and late Research \& Development functions.
\end{abstract}

Keywords: Innovation; Technology; Adoption; Implementation

\section{Introduction}

The pharmaceutical industry is today facing some major challenges. The extensive research activity of the past few decades has significantly reduced the number of opportunities to discover new drugs to address the unmet medical needs [1]. Coupled with the rising costs of Research and Development (R\&D) activities [2,3] and the increased competition from traditional industry competitors and generic manufacturers $[4,5]$ the difficulty these powerhouses face to develop robust and sustainable drug pipelines is increasing fast.

Despite spending more on $R \& D$ as a percentage of sales than any other high-tech industry [6-8], the internal innovation record of large pharmaceutical companies continues to decline. Following a significant increase in pharmaceutical R\&D expenditure over the past decade [9] [10], the number of new drug approvals has actually fallen during this period.

With an increasing amount of externally sourced innovations, a major success factor for the pharmaceutical companies will lie in how the innovations are adopted, i.e. integrated into existing $R \& D$ processes [11]. This places a premium on management of $R \& D$ activities and requires that strong initiatives are developed to maximise the value of externally sourced innovations [12].

A large amount of research has focussed on the factors that need to be considered when sourcing innovations from external parties [13-16]. This has allowed companies to develop effective processes to search for and strike deals with external companies to in-source the desired innovations. However, in order to capture and maximise value from in-sourced innovations, companies must understand how to manage their innovation implementation processes, truly leveraging the innovation within their own organization. Otherwise the large investments made when sourcing innovations will be put under extreme risk and companies may start to fall behind in their race to fill the innovation deficit [17].

Herein, we follow the definition [18, p. 1055] "innovation implementation within an organization is the process of gaining targeted employees' appropriate and committee use of an innovation. Innovation implementation presupposes innovation adoption that is, a decision, typically made by senior managers, that employees with- 
in the organization will use the innovation in their work".

The implementation stage plays a central role for innovation effectiveness [19], but relatively little research has focussed on its key success factors. Several authors have bemoaned this point, stating that research on the implementation of innovations is both labor intensive and rare [20,21].

As highlighted in the definition above, adoption is the next step towards the ultimate goal of innovation effectiveness [18]. The existing adoption frameworks can be divided into those that placed an emphasis on improving adoption by creating a strong climate for implementation and those that focused on improving adoption by developing the learning capabilities of the organization. Extant literature largely focuses on the adoption of IT technologies within companies. This work describes the determinants of a process where employees make a conscious decision to use optional technologies to perform their daily job duties.

The pharmaceutical setting poses a particular challenge in complexity of external innovation adoption and implementation as external processes, methods and technologies from various sources often have to then to be combined internally to be successfully applied. For what is meant by innovation we follow the definition that it resembles a technology or a practice, which is used for the first time by an organization's members, whether or not it has been used in other organizations previously $[18,22]$. Concerning type of innovations for the pharmaceutical setting these can be processed, technology and method innovations that are coming in from external into the focal company's R\&D functions, with the ultimate goal to facilitate output in terms of new molecular entities (NMEs). This pressure to innovate paired with process complexity to bring in these external innovations make the pharmaceutical industry an extreme case setting to study innovation implementation

Therefore, we put our focus on the following two research questions:

1) Which key determinants for innovation implementation can be identified within a pharmaceutical setting?

2) How can these be brought into a performance measurement system for steering?

In the literature review, we outline existing models of innovation implementation and summarize known determinants of success. Then, the results of expert interviews and a survey within the case company are presented. In total a number of 25 participants were interviewed and 67 took part in a survey. Central to the analysis is an assessment of how the company's climate for innovation implementation, driven by organisational, managerial and team factors can affect implementation, taking into account both the views of managerial and technical employees. Focus lies on enhancing the under- standing of the factors influencing innovation implementation in pharmaceutical companies, in order to foster improved innovation management capabilities and being able to bring them into a performance measurement framework. Lastly, we discuss the theoretical and managerial implications, reflect on limitations and provide an outlook for further research.

\section{Literature Review}

\subsection{Adoption Climate Frameworks}

Klein \& Sorra [18] presented a framework that discussed the determinants and consequences of IT adoption within organizations. Their framework hypothesized that the main determinants of innovation effectiveness are a company's climate for implementation and the congruence between the innovation and the employees' values. The framework states that both determinants need to be satisfied in order for adoption to be successful. A number of factors were provided for each determinant, some of which have strong relevance to innovation implementation projects within pharmaceutical companies. A company's climate for innovation was discussed to be dependent on factors such as the quality and usability of technology support systems and the availability of rewards and incentives for innovation implementation. Several authors have performed studies to test the principles of this article, each generally agreeing with the study findings [19,23,24].

The original framework proposed by Klein \& Sorra [18] was later extended by Klein, Conn \& Sorra [25] to include three additional, but associated determinants. The later model introduced the importance of management support along with the availability of financial resources and implementation policies and practices. The level of management support is an essential requirement for implementation success, especially the buy-in from senior management.

Similarly, the availability of implementation policies and practices is also a vital factor of implementation success. Proper processes that guide the direction of the implementation, handle the required knowledge and document key learnings need to be available to support implementation projects. The framework proposed by Frambach \& Schillewaert [26] describes the adoption and acceptance of organizational innovation from a marketing perspective and proposed that numerous factors can affect individual adoption rates. They hypothesized that organizational facilitators are an important feature of an innovation implementation framework as organizations need to provide the training and support systems to guide implementation projects.

Each of the above frameworks has demonstrated that 
adoption effectiveness can be affected by both organizational factors, relating to support infrastructure, resources and policies, and personal factors, relating to attitude, values and beliefs towards innovation.

\subsection{Learning Organization Frameworks}

Murray \& Blackman [27] introduced a holistic model hypothesizing that social architecture and learning processes are the key determinants of innovation implementation success. A company's social architecture can be created by the existence of knowledge communities that are supported by strong inter-department communication channels. Murray \& Blackman [27] moreover argued that a strong social architecture leads to wide sharing of knowledge and promotes innovation, whilst a weak social architecture leads to pockets of learning, low sharing of knowledge and lost opportunities. Organizations that have the ability to disseminate knowledge quickly throughout the company stand a much stronger chance of innovation success than those whose knowledge is deeply embedded within distant parts of the company. This is an important principle that treats knowledge not as a commodity that amassed alone will lead to innovation success, but as something that needs to be nurtured by an organization and actively shared.

Following on from this point, Cummings \& Teng [28] produced a framework that detailed the factors influencing the transfer of knowledge between organizations. Knowledge transfer is especially relevant to innovation as an extensive amount of knowledge typically needs to be transferred during these projects. Cummings \& Teng [28] proposed that knowledge transfer success is determined by four contextual domains. The recipient context highlights the need for companies to develop a learning culture that highly values innovation. This is an important determinant of knowledge transfer success that can be influenced by organizations. The other relevant domain discusses the importance of quality and usable systems to support the knowledge transfer.

Within the literature on open innovation, a major stream of research has addressed external innovation adoption and considered determinants such as environmental turbulence, technological newness, technological distance and prior cooperation [29]. This literature has also included a detailed assessment of knowledge capabilities for open innovation describing among others the following six 'knowledge capacities' needed for external innovation adoption: inventive, absorptive, transformative, connective, innovative, and desorptive capacity [30].

\subsection{Reflecting on the Literature Review}

Like many of the mentioned studies, much of the available research has focused on the adoption of new IT technologies introduced into a company to achieve a general organizational goal $[18,19,25,31-36]$. The literature on the Technology Acceptance Model [37] from the IT context and its extensions has described individuallevel (but related to the overall organization) determinants such as perceived usefulness, perceived ease of use, subjective norm [38] and psychological safety (perceived tutor support and perceived peer support) [39].

Here the definition of adoption implies that users have a choice whether or not to use the technology to perform their job duties. There is a considerable difference between adoption of new technologies available for an employee's use and the implementation of technologies in-sourced by a company to develop specific organizational capabilities. In the first, the choice of implementation does not exist and users simply need to implement the innovation in order to realize its intended purpose. For the latter case, the importance level of the implementation project is higher and requires that a much more systematic approach is developed in order to achieve implementation success.

Moreover, Stock \& Tatikonda [40-42] and their external technology integration model have studied how organizational interaction and technological uncertainty as well as contextual factors influence success of external technology integration. Zammuto \& O'Connor [43] have examined the role of organization culture and organizational structure affect manufacturing technology implementation.

In this study we focus on concrete determinants more than contextual factors. As they particularly allow to put focus on determinants of fostering a climate for adoption as the basis for our data collection the learning organization frameworks were taken, i.e. the innovation climate framework of Klein \& Sorra [18] and Frambach \& Schillewaert [26] as an extension of this framework. The literature review has allowed a list of potential factors influencing innovation implementation to be assembled. These factors have been grouped into three major categories based on their general characteristics (Table 1).

\section{Methodology}

\subsection{Research Method and Data Collection Setting}

An explorative approach is needed here, as the pharmaceutical context has not yet been analysed regarding its main innovation implementation determinants. Moreover, as we focus on "why" (why are some implementations more successful than others, what are the determinants?) and "how" (how can it be measured how well the climate for innovation implementation is?) questions, a case study approach was regarded as particularly valuable $[44,45]$ 
Table 1. Consolidated output of the literature review detailing the key factors of innovation implementation success.

\section{Category 1-Organisational Factors}

- A company culture that highly values innovation and novelty

- The company openly accepts externally developed innovations

- The company is set-up to be a learning organisation

- The quality and usability of the knowledge management systems

- The quality and usability of the technology support infrastructure (processes)

- The level of training provided to the team members

- The level of rewards available if the technologies are well implemented

- The level of non-tangible benefits available (e.g. recognition) if the technologies are well implemented

\section{Category 2-Managerial Factors}

- The clarity of project goals established so that each team member understands their role

- The regularity of project updates meetings to discuss project progression

- The timelines given to experiment with and implement the innovative technology

- The effectiveness of communication channels to discuss project issues

- The level of buy-in from senior management throughout the life of the project

- The level of motivation given to the project team

- The amount of exchange with the external partner to transfer key knowledge

- The amount of face-to-face time spent with the external partner to discuss the project on an informal basis

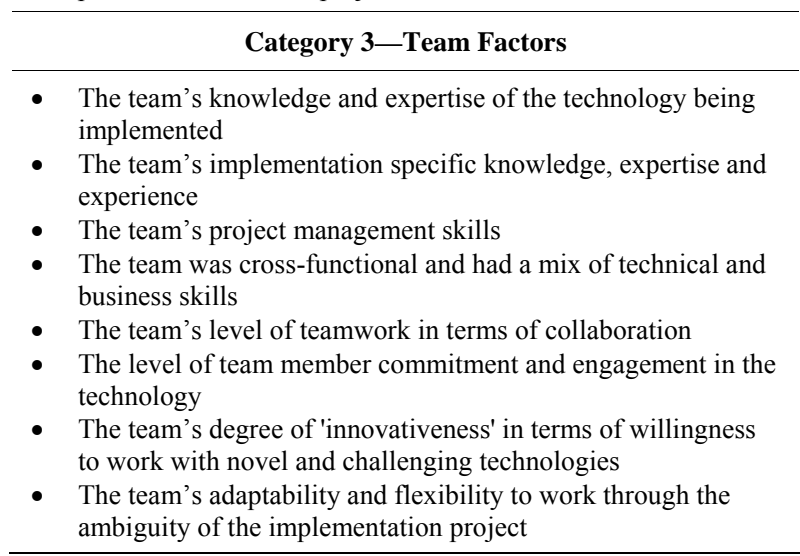

[46] for this research.

The data collection was performed based on the literature review, conducting interviews and performing a follow-up survey. The setting of the study is in the pharmaceutical industry and the interviewees and survey participants all come from this company. The case company is one of the large pharmaceutical firms, with over 35,000 employees worldwide and in the remainder of the text will be referred to as Pharma1. Pharmal is a typical pharma player in as far as it follows standardized rules and procedures. It is subject to the same trends as the other major size players it competes with, as it does compete in major therapeutic areas, not any special niche only. Within the company the development functions where in focus: Global Therapeutic Research, Lead Generation \& Optimization, Biologics, Early Development, Chemistry Manufacturing and Control. The external innovations to be implemented are usually brought in via implementation projects and they concern process, method or technology innovations.

As highlighted earlier, the pharmaceutical industry is under particular pressure to increase innovation output. Moreover, it is itself a science-based and knowledgeintensive industry. The innovation setting is particularly complex as what we study here-external processes, methods and technology innovations coming in-are usually combined internally before they are successfully implemented. Therefore, it provides an extreme case setting for innovation implementation.

\subsection{Data Collection}

Based on the review of extant models, the interview outline considered factors on three main levels; 1) Organizational factors, 2) Managerial factors, 3) Team factors. Therefore, information on key determinants of implementation success was gathered from a range of organizational perspectives. We then developed structured interview questions and a survey questionnaire to evaluate these factors.

Semi-structured interviews were performed with 25 managers and consultants from the case company to determine which of the proposed factors from the literature review had a major impact on innovation implementation success. All interview partners selected had recently managed or been the primary sponsor of projects involving the implementation of in-sourced innovations. A representative selection was targeted, so that the head of the individual development functions (Head of Global Therapeutic Research; Head of Lead Generation \& Optimization; Head of Early Development; Head of Biologics; Head of Chemistry Manufacturing and Control) and at least 2 - 4 representatives of these functions (Department Heads and Team Leaders) were interviewed.

We designed the interview method to elicit factual responses on the determinants by asking the interview partners to provide specific examples from their recent experiences and not general opinions. Once the interviews were complete, the output from the interviews was transcribed and coded (e.g. [46-48]).

An online survey with a six point scale was developed to include a broader base of the organization to assess the importance of factors, complementing the interview findings. The initial list of factors developed from the literature review was augmented with the key interview findings to produce the survey content. The respondents were selected from the interview partners' teams and 
were specifically chosen as to whether they had recently been part of technology implementation projects. The survey was sent out to 140 people within the organization and 67 responses were obtained. This resembles a response rate of approx. $48 \%$. The participation was rather high here, as the cascade ran through the earlier interviewees who distributed the survey among their teams and peers. Moreover, all received questionnaires were filled-in completely.

\section{Results of Analysis}

\subsection{Interview Results}

A wide range of factors influencing the success of implementation projects were obtained from the interviews. The overall findings are shown consolidated in Table 2.

\subsection{Survey Results}

An overall ranking of the survey results is presented in Table 3.

\section{Discussion of Results}

The analysis has shown that a number of factors can impact the effectiveness of innovation implementation within pharmaceutical companies. An important determinant of success is the existence of a company culture that is open to external innovation and committed to adopting technologies that have been developed by external companies. The study results showed the importance of scientists not harbouring a sentiment of "not invented here" or a degree of scepticism when working on external projects. This finding builds on the research performed on the topic of 'not invented here' that has highlighted the potential reduction in innovation performance if researchers under-prioritise external innova- tion projects [49-51]. Interestingly, the case study interviews and survey revealed that the sentiment towards external innovation is not homogenous throughout the company. The 'not invented here' syndrome was found to be more prevalent in the early research departments of the company, who typically need to create ideas from their own concepts and are not so accustomed to working on ideas developed by others, than for the late development functions, who typically work on partially developed ideas that have passed through the development process from the early research functions. Consequently, the latter are more open to work on ideas they have not developed themselves. This inter-departmental difference in mentality has not been discussed in the current literature and adds an interesting finding to the existing knowledge. Therefore, we propose:

Proposition 1: Innovation implementation resistance for external (process, method or technology) innovation implementation will be higher for early research than for late development functions at pharmaceutical companies.

The case study also showed that the learning capabilities of Pharmal are an important requirement for implementation success. The interview findings showed that certain functions of Pharmal operate with a silo mentality and are not well established at sharing ideas, knowledge and experiences in a cross-functional manner. Therefore, we propose:

Proposition 2: Taking into account both the views of managerial and technical/scientific/expert employees at pharmaceutical companies is essential for external (process, method or technology) innovation implementation, because their focuses can divert.

The results also found that the company's learning ca pabilities need to be supported by effective systems and processes that actively promote the required ideas and

Table 2. Consolidated summary of the interview findings.

\begin{tabular}{|c|c|c|}
\hline Key Success Factors & Commonly Encountered Obstacles & Areas of Improvement \\
\hline $\begin{array}{l}\text { 1) Company culture that is open to external } \\
\text { innovation } \\
\text { 2) Innovations that fill a direct need within the } \\
\text { company } \\
\text { 3) Strong project management with clear goals } \\
\text { Sufficient time to experiment and build } \\
\text { competence with the new technology } \\
\text { 4) Frequent communications to maintain senior } \\
\text { management buy-in - project champions are } \\
\text { vital for long-term success } \\
\text { 5) Strong working relationships with external } \\
\text { development partners to support knowledge } \\
\text { transfer } \\
\text { 6) Project teams with the required level of skills } \\
\text { diversity and experience } \\
\text { 7) Committed and enthusiastic scientists with } \\
\text { the required mentality for external technologies }\end{array}$ & $\begin{array}{l}\text { 1) There is often a degree of scepticism } \\
\text { towards ideas developed outside the } \\
\text { company } \\
\text { 2) There is insufficient support from } \\
\text { knowledge management systems within the } \\
\text { company } \\
\text { 3) Working with external partners is } \\
\text { extremely difficult and requires a lot of } \\
\text { effort to create effective partnerships } \\
\text { 4) It is hard to find people with both } \\
\text { technical and managerial skills to manage } \\
\text { external collaborations }\end{array}$ & $\begin{array}{l}\text { 1) Become a stronger learning organisation } \\
\text { that shares knowledge, ideas and experiences } \\
\text { more efficiently (remove the silo mentality) } \\
\text { 2) Create more IT tools to support learning } \\
\text { especially in the area of technology transfer } \\
\text { 3) Adapt the approach to performance } \\
\text { management to provide more recognition for } \\
\text { strong scientific achievements } \\
\text { 4) Be more flexible with early timelines and } \\
\text { allow time to experiment with new } \\
\text { technologies } \\
\text { 5) Develop more schemes to enhance the } \\
\text { working relationships with external partners } \\
\text { 6) Provide employees with } 100 \% \text { dedicated } \\
\text { time to work on implementation projects }\end{array}$ \\
\hline
\end{tabular}


Table 3. Ranking of the factors from the survey data.

\begin{tabular}{|c|c|c|}
\hline Rank & Factor & Score \\
\hline 1 & The amount of input and exchange with the external partner & 2.22 \\
\hline 2 & The level of team member commitment, and interest in the technology & 2.22 \\
\hline 3 & The company culture highly values innovation and novelty & 2.17 \\
\hline 4 & The clarity of project goals established with the project team & 2.17 \\
\hline 5 & The level of buy-in from senior management & 2.06 \\
\hline 6 & The timelines given to experiment with the innovative technology & 1.94 \\
\hline 7 & The amount of informal face-to-face time spent with the external partner & 1.94 \\
\hline 8 & The project team's degree of 'innovativeness' & 1.94 \\
\hline 9 & The company is set-up to be a learning organisation & 1.94 \\
\hline 10 & The company openly accepts externally developed innovations & 1.78 \\
\hline 11 & The level of training provided to the team members & 1.76 \\
\hline 12 & The regularity of project update meetings & 1.61 \\
\hline 13 & The project team's adaptability and flexibility & 1.59 \\
\hline 14 & The project team's implementation specific knowledge and experience & 1.50 \\
\hline 15 & The effectiveness of communication channels & 1.33 \\
\hline 16 & The project team's level of teamwork & 1.24 \\
\hline 17 & The level of motivation given to the project team & 1.22 \\
\hline 18 & The project team's knowledge and expertise of the technology & 1.22 \\
\hline 19 & The quality and usability of the technology support infrastructure & 1.22 \\
\hline 20 & The project team was cross-functional & 1.06 \\
\hline 21 & The level of non-tangible benefits available (e.g. recognition) & 0.94 \\
\hline 22 & The project team's project management skills & 0.89 \\
\hline 23 & The quality and usability of the knowledge management systems & 0.78 \\
\hline 24 & The level of financial rewards available (e.g. bonuses) & -0.06 \\
\hline
\end{tabular}

knowledge sharing. This point was discussed by Murray \& Blackman [27] who emphasized the importance of routines and processes on innovation management. The lack of a consolidated knowledge management system within the company adds significant and somewhat unnecessary complexity to implementation projects. A key example of this relates to the company's current approach to technology transfer. No formal system exists to aid the transfer of key project information from external partners and consequently all efforts need to be performed on an ad-hoc basis. This makes the process significantly less efficient and can result in key information not being transferred. The framework developed by Cummings \& Teng [28] provides a solid summary of the key factors of effective technology transfer. The findings derived from our study add a new layer to this knowl- edge and highlight that support systems are more important for the late stage functions of pharmaceutical companies than for the early stage research functions. One of the key factors driving this is that the late development functions need to work in a more regulated environment and ensure that all aspects of their work are compliant with the strict regulatory requirements. Therefore we propose:

Proposition 3: Support systems are more important for late stage than for early stage functions for external (process, method or technology) innovation implementation at pharmaceutical companies.

Another major determinant of implementation success was the effectiveness with which the company interacts with external development partners. The ability of the company to form effective working relationships with 
external partners will be a vital factor in determining the success of future open innovation efforts. Relationships with external partners can be difficult, largely due to the lack of face-to-face time spent together during the projects that makes goal alignment and communications more difficult. An extensive amount of research has focussed on collaboration management and has found that the need to develop common goals early, create mechanisms of interaction and build trust are some of the key determinants of success [52-54]. Here, the results highlighted that the complexity of projects played a vital role for how critical for project success the relationship with the external party is. Therefore, we propose:

Proposition 4: For external (process, method or technology) innovation implementation the relationship with the external party is particularly important for highly complex innovations with which pharmaceutical companies have little existing knowledge.

Strong and frequent communications throughout all levels of the organisation was also found to be a major determinant of implementation success. It is especially important to communicate extensively with senior management to maintain a high level of buy-in and ensure that the project is properly championed. The study has also found that company-wide communication efforts are important, especially for highly novel technologies with which the company has little existing knowledge. Therefore, we propose:

Proposition 5: For external (process, method or technology) innovation implementation companywide communication efforts are particularly important for highly novel innovations with which pharmaceutical companies have little existing knowledge.

Other project management requirements derived from the study include the need to dedicate resources from the functional teams to work on the implementation project. It is too ambitious to expect employees to perform their day-to-day duties in addition to tackling complex and uncertain implementation projects. Additionally, sufficient time should be provided to the project team to experiment with the innovation and develop sufficient confidence in the technology before committing to solid project aims. This can be difficult as significant timeline pressure is placed on projects to drive quick completion of tasks. However, rushing into the use of novel technologies without a full understanding of their operating capabilities can lead to significant delays once the project is running at full pace. Investing time up front to de-bug the technology and fully understand is operating limits could reap significant long-term benefits. Therefore, we propose:

Proposition 6: Sufficient time to experiment with the external novel (process, method or technology) innovation entering the pharmaceutical company should be provided before concrete project aims for implementation are committed.

A final requirement for success is to have the people working on implementation projects that possess the required skills and mentality towards external innovation. Even with the best implementation strategy in place, it is the people working on the project making things happen. It is therefore essential to select strong teams to work on implementation projects that possess a diverse range of skills. These need to include strong technical and business skills to effectively manage all aspects of external collaborations. In almost all cases discussed during the interviews, employees working on implementation projects had the required level of technical skills to complete the projects, but often lacked the required business skills to effectively manage the project. Therefore, we propose:

Proposition 7: For external (process, method or technology) innovation implementation the project team members need to possess both the technical and the business skills.

\section{Towards Successful Innovation Implementation and Measurement}

\subsection{Towards Successful Innovation Implementation}

The key findings from the literature review and interviews and survey at Pharmal were used to develop the innovation implementation framework (Figure 1). The framework is divided into four sections, relating to the roles the different levels of the organisation must play in order to achieve successful adoption.

The first level of the framework describes the role the organisation must play to create a strong climate for implementation. These factors are highly structural and consequently need to act as the foundation on which successful innovation implementation is based. Systems and initiatives should be created to help the company improve its learning capabilities and allow the benefits of lessons learnt to be fully leveraged.

Organisations also need to develop the internal processes and systems to support implementation projects. This requires a consolidated approach to knowledge management consisting of fully accessible databases that are capable of handling complex and sensitive project data. Robust technology transfer platforms also need to be established to ensure that important project related information can be transferred efficiently and effectively from the external partner.

A major emphasis also needs to be placed on enhancing the collaboration management capabilities of the company so that effective relationships can be developed with external partners. People exchanges and other such initiatives that increase the interaction during projects 
Innovation implementation framework

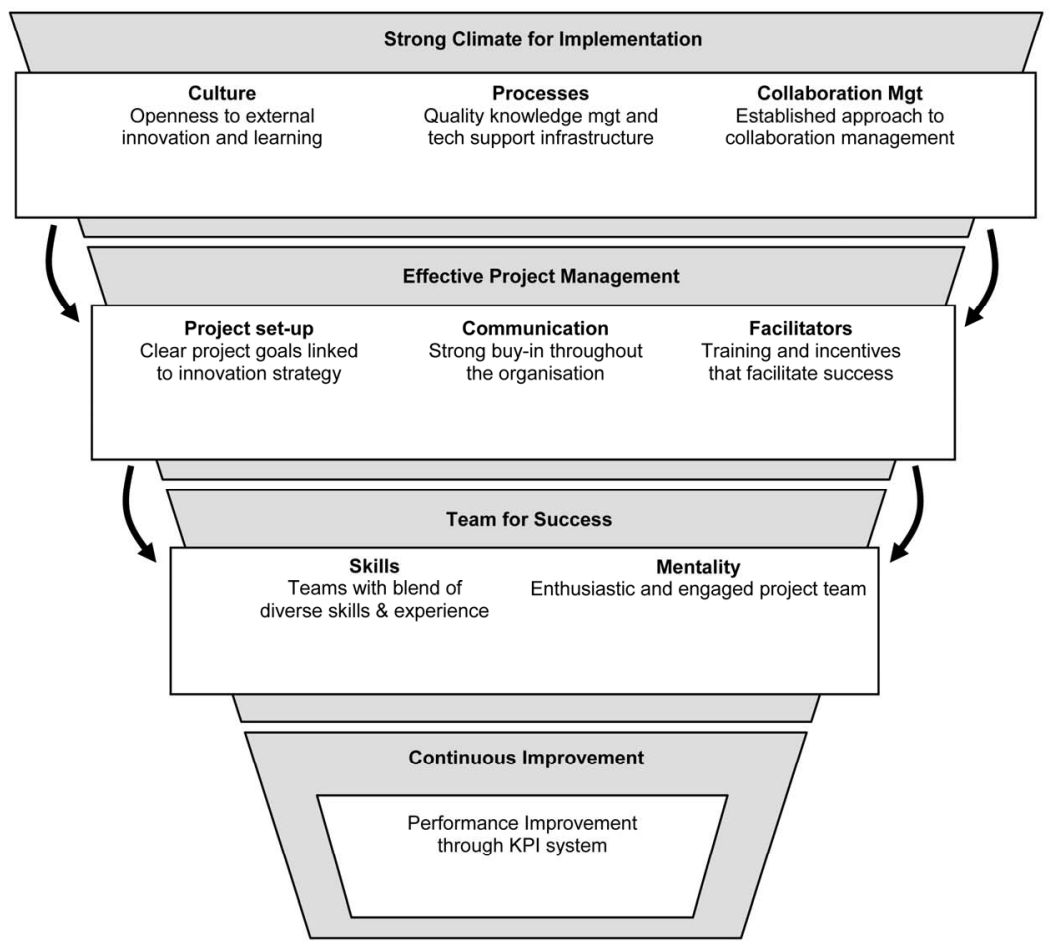

Building blocks for success

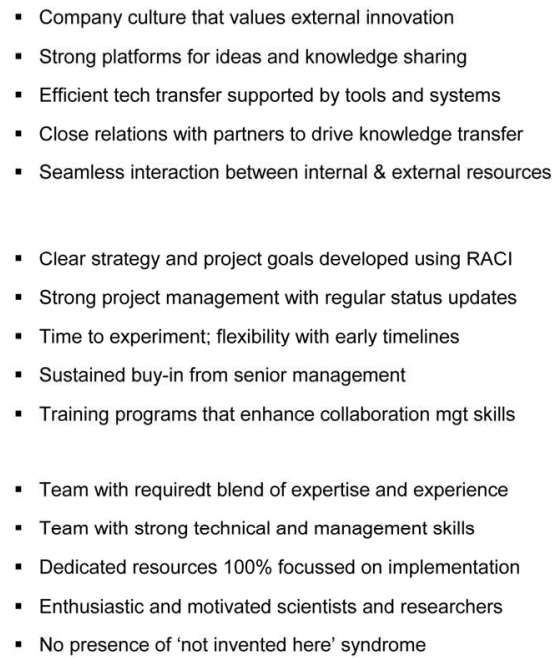

Figure 1. Framework and associated building blocks for success.

should be utilised to enhance the working relationship between the two parties and help to create a seamless exchange of information.

The second level of the framework describes the role managers play to execute implementation projects effectively. Central to this level is the need for project managers to set clear implementation project goals that are linked to the innovation strategy of the company and align all major stakeholders. Sufficient time to experiment and develop real competence with the innovation should be worked into the project plan before solid project commitments are made.

Project managers leading implementation projects also need to establish strong and effective communication channels to maintain a high level of interest and awareness in the project throughout the organisation. Sustained senior management buy-in is essential to champion the project and ensure that it is properly supported.

The third level of the framework highlights the importance of selecting the team for implementation projects that possesses the required blend of skill diversity and mentality for implementation projects. These factors are directly influenced by the major elements in the preceding two levels. A wide range of skills must be present in implementation project teams, including strong technical and managerial skills.

The attitude of the team members is also a vital re- quirement for implementation success. This point is largely dictated by the company culture and the level of motivation provided by managers. It is unrealistic expect employees to be fully focussed on complex implementation projects if they need to conduct these on top of their daily job duties. The final level of the framework describes the importance of establishing performance improvement initiatives through a well-developed KPI (Key Performance Indicator) system. This will drive the continuous improvement of implementation initiatives and will improve the company-wide learning and development of such activities.

\subsection{Towards Successful Performance Measurement}

To improve the implementation capabilities of companies and strive for continuous improvement, the findings about the main determinants identified were translated into a balanced scorecard KPI framework. In order to be relevant to external innovations, both internal and external focussed metrics needed to be included along with both short and long-term measures [55-63]. Key performance indicators for each of the four perspectives of the balanced scorecard are presented in Figure 2.

The internal business process metrics measure the overall effectiveness of implementation projects. Firstly, they assess the time taken to complete the implementa- 


\begin{tabular}{|l|l|}
\hline \multicolumn{2}{|c|}{ Internal Business Processes } \\
\hline \multicolumn{1}{|c|}{ Indicator } & \multicolumn{1}{c|}{ Description } \\
\hline $\begin{array}{l}\text { Implementation } \\
\text { project time }\end{array}$ & $\begin{array}{l}\text { Time taken to complete the implementation project } \\
\text { (relative to expected timelines) }\end{array}$ \\
\hline $\begin{array}{l}\text { Usage of } \\
\text { technology }\end{array}$ & $\begin{array}{l}\text { Amount of usage of the technology on the } \\
\text { intended and future projects }\end{array}$ \\
\hline $\begin{array}{l}\text { Improvement } \\
\text { realisation }\end{array}$ & $\begin{array}{l}\text { Degree to which the intended improvements were } \\
\text { provided by the technology }\end{array}$ \\
\hline
\end{tabular}

\begin{tabular}{|l|l|}
\hline \multicolumn{1}{|c|}{ Financial } \\
\hline \multicolumn{1}{|c|}{ Indicator } & \multicolumn{1}{c|}{ Description } \\
\hline Project cost & $\begin{array}{l}\text { Financial resources required to complete the } \\
\text { project (relative to budget) }\end{array}$ \\
\hline $\begin{array}{l}\text { Alliance mgt } \\
\text { resources }\end{array}$ & $\begin{array}{l}\text { Financial resources spent on Alliance } \\
\text { Management activities }\end{array}$ \\
\hline Incentives & $\begin{array}{l}\text { Amount of financial incentives supplied to the } \\
\text { project team members }\end{array}$ \\
\hline $\begin{array}{l}\text { Productivity } \\
\text { gain }\end{array}$ & Improvement of input to output ratio \\
\hline
\end{tabular}

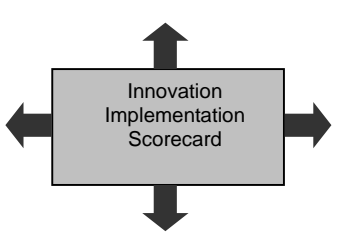

\begin{tabular}{|l|l|}
\hline \multicolumn{2}{|c|}{ Customer } \\
\hline \multicolumn{1}{|c|}{ Indicator } & \multicolumn{1}{c|}{ Description } \\
\hline $\begin{array}{l}\text { Internal cust. } \\
\text { satisfaction }\end{array}$ & $\begin{array}{l}\text { Satisfaction level of the internal customer, i.e. } \\
\text { the function receiving the technology }\end{array}$ \\
\hline External cust. & $\begin{array}{l}\text { Satisfaction level of the external customer, i.e. } \\
\text { the technology partner }\end{array}$ \\
\hline satisfaction & $\begin{array}{l}\text { Proportion of employees with a positive } \\
\text { sentiment towards external innovations }\end{array}$ \\
\hline Employee \\
sentiment
\end{tabular}

\begin{tabular}{|l|l|}
\hline \multicolumn{1}{|c|}{ Learning and Growth } \\
\hline \multicolumn{1}{|c|}{ Indicator } & \multicolumn{1}{c|}{ Description } \\
\hline $\begin{array}{l}\text { Training } \\
\text { supplied }\end{array}$ & $\begin{array}{l}\text { Number of days training supplied to develop skills } \\
\text { required to complete the project }\end{array}$ \\
\hline $\begin{array}{l}\text { Use of lessons } \\
\text { learnt }\end{array}$ & $\begin{array}{l}\text { Number of projects that incorporated lessons } \\
\text { learnt into the initial project plan }\end{array}$ \\
\hline $\begin{array}{l}\text { Tech transfer } \\
\text { efficiency }\end{array}$ & $\begin{array}{l}\text { Time taken to complete the technology transfer } \\
\text { activities }\end{array}$ \\
\hline
\end{tabular}

Figure 2. Innovation implementation balanced scorecard.

tion project relative to the expected timelines. This will allow any delays in the process to be identified and help to find ways of reducing future occurrences. The longterm effectiveness of the implemented technology can be evaluated by measuring the extent to which the technology achieved its intended goals, e.g. increased speed or reduced cost. The overall usage of the technology on the intended and future projects will also measure how integrated and valuable the process, method and/or technology innovation has become at improving the long-term internal capabilities of the company. The customer metrics measure the satisfaction of both internal and external customers with the way the project was run. Internal satisfaction measures whether the key requirements of the function receiving the technology have been met.

The external view measures the satisfaction of the external innovation partner and gauges the possibility of conducting future projects with the company. It is important to maintain good links to external partners as a major requirement of future innovation success will be the company's reputation as being a partner of choice for innovation projects. The employee sentiment measures the motivation of employees and their willingness to work on external innovation projects. This will allow the openness of the company to work with external innovation to be measured over time.

The learning and growth metrics measure how the ability of the company to successfully conduct implementation projects has improved over time. This firstly measures the number of days training provided to team members to develop important implementation related skills or to attend relevant conferences. It also measures the company's learning capabilities by assessing the number of projects that gained input from the lessons learnt from previous implementation attempts. The time taken to complete the technology transfer process can be measured to assess what improvements have been made by the company to complete this important pre-requisite of implementation success.

The financial metrics measure financial aspects of the project. The total amount of financial resources spent on the project relative to budget can be measured to ensure projects are being operated cost efficiently. The amount of resources dedicated to alliance management activities can also be measured to determine whether this important step is properly supported. Although not a major driver of performance, the level of performance-based rewards provided to the team can be measured to keep track of this metric.

\section{Conclusions}

\subsection{Theoretical Implications}

The initial research questions that guided this study were the following: 1) Which key determinants for innovation implementation can be identified within a pharmaceutical setting? 2) How can these be brought into a performance measurement framework for steering?

Regarding question 1 the results in Tables 2 and 3, as well as the multilevel framework shown in Figure 1 highlight that it is necessary to take into account all four levels of establishing a strong climate for implementation, 
ensure effective project management, build teams for success and promote continuous improvement.

Regarding question 2, and in order to facilitate the application of the determinants shown in Figure 1, the measurement framework was developed in order to foster respective action. The exemplary measurement framework was illustrated in Figure 2.

The findings of this study have agreed with important factors identified in previous research in other industry settings, but have also revealed a number of new insights. Summarizing the interview and survey findings, the following insights were generated (also summarized in our propositions): First, the openness of employees to work with externally developed technologies was much stronger for the late development functions than for the early research departments. Second, manager and employee perception may vary considerably and so both perspectives should be taken in. Third, projects involving comparatively later development require more support from formal systems and processes than those involving more early research. Fourth, external partner relationships gain in importance the more complex the incoming innovation is (a finding which is only new as this is the first study in the pharmaceutical context, but well-established for example in the strategic alliance literature). Fifth, significantly more communication and awareness building is required for highly novel technologies than for those that are well-established. Sixth, project team members need to possess both the required technical and business skills.

\subsection{Practical Implications}

Regarding managerial implications, it can be said that this study offers a number of interesting and practical insights for managing external innovation implementation, specifically in the pharmaceutical industry.

First, the developed determinant framework (Figure 1) provides guidance on dimensions and factors influencing innovation implementation. Although they may have different relative importance depending on the individual company, the general overview provides a starting point for internal discussions towards customization. Second, the exemplary innovation implementation measurement framework can also serve as a practical tool to then monitor and steer the determinants. In that sense it is a diagnostic tool, but also a managerial tool at the same time.

All in all, several contextual factors were highlighted to have a moderating role towards the innovation implementation situation: Complexity and novelty do play a role for the implementation approach to be taken for project at hand. This should be taken into account deliberately by managers, e.g. being more prepared to allocate more dedicated resources for projects at the high com- plexity and/or high novelty end. Moreover, assigning people with both the technical and the business skills necessary to projects was highlighted. And, last but not least, the study showed that managerial and employee perceptions varied. Therefore, feedback loops should be established that enable that both views are feeding into communication and performance measurement tools such as the balanced scorecard approach shown in Figure 2, to foster future mutual understanding and congruence of objectives.

\subsection{Limitations and Suggestions for Further Research}

The data were collected in a large pharmaceutical company. The company is a typical pharmaceutical player with no unusual product portfolio and follows standard practices. Therefore, for the pharmaceutical setting we think our results are basically applicable, for example when it comes to the findings about the differences between early and later development functions. Moreover as mentioned initially, the pharmaceutical setting poses an extreme case setting due to the fragmentation of multiple process, method and technological innovations that are brought in in order to be combined. Therefore, the main findings here should be basically applicable to other knowledge-intensive, R\&D-focused industries, too. In future, studies across several firms as well as crossindustry would be recommendable to gain further insights.

Although a section was provided in the questionnaire to indicate the type of project on which the responses were being based, sufficiently distinct descriptions were not obtained to allow an assessment of the survey findings by project type. This would have provided useful data to build on the results identified in the interviews. Therefore, this is one of our suggestions for further research.

Moreover, the balanced scorecard has provided a comprehensive list of indicators that can be used to measure the performance of innovation implementation projects. However, in order to be fully effective, details of how to measure each individual indicator have to be established. This requires detailed benchmarking analyses and significant implementation experience to determine the optimal measure for each indicator and the target values. Consequently, the current balanced scorecard can be viewed as an initial frame for the important metrics of implementation success, to be individually developed towards a full KPI system.

Although a core group of factors/obstacles were common for each project discussed it mattered whether the technology was simple or complex, integrated into early stage research or late stage development, or was generally known or unknown amongst the company's scien- 
tists. Therefore, these aspects deserve more attention in future studies as well.

\section{REFERENCES}

[1] E. F. Schmid and D. A. Smith, "Pharmaceutical R \& D in the Spotlight: Why is There Still Unmet Medical Need?" Drug Discovery Today, Vol. 12, No. 23, 2007, pp. 9981006. doi:10.1016/j.drudis.2007.08.013

[2] M. Dickson and J. P. Gagnon, "Key Factors in the Rising Cost of New Drug Discovery and Development," Nature Reviews Drug Discovery, Vol. 3, No. 5, 2004, pp. 417-429. doi:10.1038/nrd1382

[3] M. D. Rawlins, "Cutting the Cost of Drug Development," Nature Reviews Drug Discovery, Vol. 3, No. 4, 2004, pp. 360-364. doi: $10.1038 / \mathrm{nrd1347}$

[4] T. Aronsson, M. A. Bergman and N. Rudholm, "The Impact of Generic Drug Competition on Brand Name Market Shares-Evidence from Micro Data," Review of Industrial Organization, Vol. 19, No. 4, 2001, pp. 423-433. doi:10.1023/A:1012504310953

[5] J. Lexchin, "The Effect of Generic Competition on the Price of Brand-Name Drugs," Health Policy, Vol. 68, No. 1, 2004, pp. 47-54. doi:10.1016/j.healthpol.2003.07.007

[6] PhRMA, "Profile Pharmaceutical Industry, Report," 2010. http://www.phrma.org/sites/phrma.org/files/attachments/P rofile_2010_FINAL.pdf

[7] National Science Foundation, 2009. http://www.nsf.gov/statistics/nsf00301/expendit.htm

[8] "Pharmaceutical Research and Manufacturers of America," PhRMA Annual Survey, 1997.

[9] F. J. Cohen, "Macro Trends in Pharmaceutical Innovation," Nature Reviews Drug Discovery, Vol. 4, No. 1, 2005, pp. 78-84. doi:10.1038/nrd1610

[10] O. Gassmann, G. Reepmeyer and M. Von Zedtwitz, "Leading Pharmaceutical Innovation: Trends and Drivers for Growth in the Pharmaceutical Industry," 2nd Edition, Springer, Berlin, 2008.

[11] B. Cassiman and R. Veugelers, "In Search of Complementarity in Innovation Strategy: Internal R \& D and External Knowledge Acquisition," Management Science, Vol. 52, No. 1, 2006, pp. 68-82. doi: $10.1287 / \mathrm{mnsc} .1050 .0470$

[12] L. B. Cardinal, "Technological Innovation in the Pharmaceutical Industry: The Use of Organizational Control in Managing Research and Development," Organizational Science, Vol. 12, No. 1, 2001, pp. 19-36. doi:10.1287/orsc.12.1.19.10119

[13] J. P. Liebeskind, A. L. Oliver, L. Zucker and M. Brewer, "Social Networks, Learning, and Flexibility: Sourcing Scientific Knowledge in New Biotechnology Firms," Organization Science, Vol. 7, No. 4, 1996, pp. 428-443. doi:10.1287/orsc.7.4.428

[14] R. Veugelers and B. Cassiman, "Make and Buy in Innovation Strategies: Evidence from Belgian Manufacturing Firms," Research Policy, Vol. 28, No. 1, 1999, pp. 63-80. doi:10.1016/S0048-7333(98)00106-1

[15] J. C. Linder, S. Jarvenpaa and T. H. Davenport, "Toward an Innovation Sourcing Strategy," MIT Sloan Management Review, Vol. 44, No. 4, 2003, pp. 43-49.

[16] L. Huston and N. Sakkab, "Connect and Develop-Inside Procter \& Gamble's New Model for Innovation," Harvard Business Review, Vol. 84, No. 3, 2006, pp. 58-66.

[17] PWC PriceWaterhouseCoopers Report, "Pharma 2020 Vision 2009," 2009.

http://www.pwc.com/gx/en/pharma-life-sciences/index.jh tml

[18] K. J. Klein and J. S. Sorra, "The Challenge of Innovation Implementation," Academy of Management Review, Vol. 21, No. 4, 1996, pp. 1055-1080.

[19] P. J. Holahan, Z. H. Aronson, M. P, Jurkat and F. D. Schoorman, "Implementing Computer Technology: A Multiorganizational Test of Klein and Sorra's Model," Journal of Engineering and Technology Management, Vol. 21, No. 1, 2004, pp. 31-50. doi:10.1016/i.jengtecman.2003.12.003

[20] K. J. Klein and A. P. Knight, "Innovation Implementation -Overcoming the Challenge," Current Directions in Psychological Science, Vol. 14, No. 5, 2005, pp. 243-246. doi:10.1111/j.0963-7214.2005.00373.x

[21] J. W. Hedge and E. D. Pulakos, "Grappling with Implementation: Some Preliminary Thoughts and Relevant Research," In: J. W. Hedge and E. D. Pulakos, Eds., Implementing Organizational Interventions-Steps, Processes, and Best Practices, John Wiley \& Sons, London, 2002, pp. 1-11.

[22] W. R. Nord and S. Tucker, "Implementing Routine and Radical Innovations,” Lexington Books, Lexington, 1987.

[23] J. Robertson, T. Sorbello and K. Unsworth, "Innovation Implementation: The Role of Technology Diffusion Agencies," Journal of Technology Management and Innovation, Vol. 3, No. 3, 2008, pp. 1-10.

[24] D. Linying, D. J. Neufeld and C. Higgins, "Testing Klein and Sorra's Innovation Implementation Model: An Emprical Examination," Journal of Engineering \& Technology Management, Vol. 25, No. 4, 2008, pp. 237-255. doi:10.1016/j.jengtecman.2008.10.006

[25] K. J. Klein, A. B. Conn and J. S. Sorra, "Implementing Computerized Technology: An Organizational Analysis," Journal of Applied Psychology, Vol. 86, No. 5, 2001, pp. 3-16. doi:10.1037/0021-9010.86.1.3

[26] R. T. Frambach and N. Schillewaert, "Organizational Innovation Adoption: A Multi-Level Framework of Determinants and Opportunities for Future Research," Journal of Business Research, Vol. 55, No. 2, 2002, pp. 163176. doi:10.1016/S0148-2963(00)00152-1

[27] P. Murray and D. Blackman, "Managing Innovation through Social Architecture, Learning and Competencies: A New Conceptual Approach," Knowledge and Process Management, Vol. 12, No. 3, 2006, No. 132-143.

[28] J. L. Cummings and B. S. Teng, "Transferring R \& D Knowledge: The Key Factors Affecting Knowledge Transfer Success," Journal of Engineering and Technology Management, Vol. 20, No. 1-2, 2003, pp. 39-68. doi:10.1016/S0923-4748(03)00004-3

[29] V. Van de Vrande, W. Vanhaverbeke and G. Duysters, 
"External Technology Sourcing: The Effect of Uncertainty on Governance Mode Choice," Journal of Business Venturing, Vol. 24, No. 1, 2009, pp. 62-80. doi:10.1016/i.jbusvent.2007.10.001

[30] U. Lichtenthaler and E. Lichtenthaler, "Capability-Based Framework for Open Innovation: Complementing Absorptive Capacity," Journal of Management Studies, Vol. 46, No. 8, 2009, pp. 1315-1338. doi:10.1111/j.1467-6486.2009.00854.x

[31] R. B. Cooper and R. W. Zmud, "Information Technology Implementation Research: A Technological Diffusion Approach," Management Science, Vol. 36, No. 2, 1990, pp. 123-139. doi:10.1287/mnsc.36.2.123

[32] D. P. Ely, "Conditions that Facilitate the Implementation of Educational Technology Innovations," Journal on Research on Computing in Education, Vol. 23, No. 2, 1990, pp. 298-305.

[33] E. M. Rogers, "Diffusion of Innovations," 4th Edition, Free Press, New York, 1995.

[34] P. L. Rogers, "Barriers to Adopting Emerging Technologies in Education," Journal of Computing Research, Vol. 22, No. 4, 2000, pp. 455-472. doi:10.2190/4UJE-B6VW-A30N-MCE5

[35] E. Waarts, Y. M. Everdingen and J. Hillegersberg, "The Dynamics of Factors Affecting the Adoption of Innovation," Journal of Product Innovation Management, Vol. 19, No. 6, 2001, pp. 412-423. doi:10.1016/S0737-6782(02)00175-3

[36] D. C. Ensminger, D. W. Surry, B. E. Porter and D. Wright, "Factors Contributing to the Successful Implementation of Technology Innovations," Educational Technology and Society, Vol. 7, No. 3, 2004, pp. 61-72.

[37] F. D. Davis, "Perceived Usefulness, Perceived Ease of Use, and User Acceptance of Information Technology," MIS Quarterly, Vol. 13, No. 3, 1989, pp. 319-340. doi:10.2307/249008

[38] V. Venkatesh, M. G. Morris, G. B. Davis and F. D. Davis, "User Acceptance of Information Technology: Toward a Unified View," MIS Quarterly, Vol. 27, No. 3, 2003, pp. 425-478.

[39] E. Van Raaij and J. Schepers, "The Acceptance and Use of a Virtual Learning Environment in China," Computers \& Education, Vol. 50, No. 3, 2008, pp. 838-852. doi:10.1016/i.compedu.2006.09.001

[40] G. N. Stock and M. V. Tatikonda, "The Joint Influence of Technology Uncertainty and Interorganizational Interaction on External Technology Integration Success," Journal of Operations Management, Vol. 26, No. 1, 2008, pp. 65-80. doi:10.1016/i.jom.2007.04.003

[41] G. N. Stock and M. V. Tatikonda, "External Technology Integration in Product and Process Development," International Journal of Operations and Production Management, Vol. 24, No. 7, 2004, pp. 642-665. doi:10.1108/01443570410541975

[42] G. N. Stock and M. V. Tatikonda, "A Typology of Project-Level Technology Transfer Processes," Journal of Operations Management, Vol. 18, No. 6, 2000, pp. 719737. doi:10.1016/S0272-6963(00)00045-0
[43] R. F. Zammuto and E. J. O'Connor, "Gaining Advanced Manufacturing Technologies' Benefits: The Roles of Organization Design and Culture," The Academy of Management Review, Vol. 17, No. 4, 1992, pp. 701-728.

[44] R. K. Yin, "Case Study Research: Design and Methods," Sage Publications, Inc., Thousand Oaks, 2003.

[45] I. Nonaka and H. Takeuchi, "The Knowledge Creating Company: How Japanese Companies Create the Dynamics of Innovation," Oxford University Press, New York, 1995.

[46] D. Silverman, "Doing Qualitative Research," 2nd Edition, Sage Publications, Thousand Oaks, 2004.

[47] M. Miles and A. Huberman, "Qualitative Data Analysis," Sage Publications, Thousand Oaks, 1994.

[48] D. Silverman, "Interpreting Qualitative Data: Methods for Analysing Talk, Text, and Interaction," Sage Publications, London, 1993.

[49] D. G. Marquis, "The Anatomy of Successful Innovations," Innovation, Vol. 1, 1969, pp. 28-37.

[50] R. Katz and T. J. Allen, "Investigating the Not Invented Here (NIH) Syndrome: A Look at the Performance, Tenure and Communication Patterns of $50 \mathrm{R} \& \mathrm{D}$ Project Groups," R\&D Management, Vol. 12, No. 1, 1982, pp. 720. doi:10.1111/j.1467-9310.1982.tb00478.x

[51] H. A. Simon, "Bounded Rationality and Organisational Learning," Organisational Science, Vol. 2, No. 1, 1991, pp. 125-134. doi:10.1287/orsc.2.1.125

[52] J. M. Wondolleck and S. Yaffee, "Making Collaboration Work: Lessons from Innovation in Natural Resource Management," Island Press, Washington DC, 2000.

[53] W. W. Powell, K. W. Koput and L. Smith-Doerr, "Interorganizational Collaboration and the Locus of Innovation: Networks of Learning in Biotechnology," Administrative Science Quarterly, Vol. 41, No. 1, 1996, pp. 116-145. doi: $10.2307 / 2393988$

[54] D. Littler, F. Leverick and M. Bruce, "Factors Affecting the Process of Collaborative Product Development: A Study of UK Manufacturers of Information and Communications Technology Products," Journal of Product Innovation Management, Vol. 12, No. 1, 1995, pp. 16-32. doi:10.1016/0737-6782(94)00025-B

[55] K. H. Lai, E. Ngai and T. Cheng, "An Empirical Study of Supply Chain Performance in Transport Logistics," International Journal of Production Economics, Vol. 87, No. 3, 2004, pp. 312-331.

[56] J. Ukko, J. Tenhunen and H. Rantanen, "Performance Measurement Impacts on Management and Leadership: Perspectives of Management and Employees," International Journal of Production Economics, Vol. 110, No. 1-2, 2007, pp. 39-51. doi:10.1016/j.ijpe.2007.02.008

[57] A. Neely, J. Mills, K. Platts, M. Gregory and H. Richards, "Performance Measurement Design: Should Process Based Approaches Be Adopted?" International Journal of Production Economics, Vol. 46-47, 1996, pp. 423-431. doi:10.1016/S0925-5273(96)00080-1

[58] M. Smith and D. Smith, "Implementing Strategically Aligned Performance Measurement in Small Firms," In- 
ternational Journal of Production Economics, Vol. 106, No. 2, 2007, pp. 393-408. doi:10.1016/j.ijpe.2006.07.011

[59] J. Schmitz and K. Platts, "Supplier Performance Measurement: Indications from a Study in the Automotive Industry," International Journal of Production Economics, Vol. 89, No. 2, 2004, pp. 231-243.

doi:10.1016/S0925-5273(02)00469-3

[60] R. S. Kaplan and D. P. Norton, "The Balanced ScorecardMeasures That Drive Performance," Harvard Business Review, Vol. 70, No. 1, 1992, pp. 71-79.

[61] J. Sandström and J. Toivanen, "The Problem of Managing
Product Development Engineers: Can the Balanced Scorecard Be an Answer?" International Journal of Production Economics, Vol. 78, No. 1, 2002, No. 79-90.

[62] R. Kaplan and D. Norton, "Using the Balanced Scorecard as a Strategic Management System," Harvard Business Review, Vol. 74, No. 1, 1996, pp. 75-85.

[63] S. Schmidberger, L. Bals, E. Hartmann and C. Jahns, "Development of a Performance Measurement System for the Benchmarking of Ground Handling Services at European Hub Airports," International Journal of Production Economics, Vol. 117, No. 1, 2009, No. 104-116. 